\title{
TRÊS ANÁLISES DE LINGUAGEM NO AUTISMO
}

\author{
Three language analysis in autism
}

\author{
Michele Paula Moro (1), Ana Paula Ramos de Souza (2)
}

\begin{abstract}
RESUMO
Tema: linguagem no Autismo. Procedimentos: analisar, comparativamente, dados de linguagem obtidos por meio de dois protocolos, um da interação mãe-criança e outro de atos comunicativos da criança entre si e com a análise dialógica da díade mãe-filho. Outro objetivo foi discutir as implicações de tais análises para o planejamento terapêutico. A amostra constou de três sujeitos na faixa etária de 2 anos e 1 mês a 4 anos e 6 meses, com diagnóstico de distúrbio de linguagem secundário ao espectro autístico. A coleta foi realizada por meio da filmagem de sessões de interação lúdica, de 30 minutos, dos sujeitos com suas mães. Os procedimentos de análise foram: a transcrição das filmagens, conferência das mesmas, aplicação de dois protocolos, um de análise da interação mãe-filho e outro de comportamentos comunicativos da criança, e uma análise qualitativa da atividade dialógica da díade. Resultados: os resultados do protocolo de interação mãe-filho demonstraram freqüência similar de categorias dos comportamentos das três mães, com elevado número de perguntas e de diretividade intrusiva. No mesmo protocolo, as crianças demonstraram brincar exploratório e funcional, estereotipias verbais e não verbais, fato também observado no protocolo de pragmática. $O$ protocolo de interação permite observar melhor que os comportamentos infantis e maternos possuem relações, mas apenas a análise qualitativa possibilita identificar a natureza dialética de tais relações. Conclusão: o protocolo que analisa a interação provê informações fundamentais ao planejamento terapêutico, adicionais ao protocolo de foco exclusivo no conhecimento pragmático do sujeito. Aquele protocolo, em conjunto com a análise qualitativa, permite uma seleção mais qualificada das estratégias de intervenção em cada caso.
\end{abstract}

DESCRITORES: Linguagem Infantil, Transtorno Autistico; Transtornos da Linguagem

\section{INTRODUÇÃO}

No estudo da linguagem em quadros de autismo, destaca-se a perspectiva pragmática, cujo foco é o uso apropriado da linguagem, através da análise de funções comunicativas. Tal perspectiva provém de estudos lingüísticos em pragmática que pressupõem uma competência pragmática do falante, ou seja, não basta que conheça as estruturas abstratas da língua, mas precisa torná-las funcionais no uso da linguagem ${ }^{1}$.

(1) Fonoaudióloga; bolsista Serviço de Atendimento Fonoaudiológico da Universidade Federal de Santa Maria; Mestranda em Distúrbios da Comunicação Humana na Universidade Federal de Santa Maria.

(2) Fonoaudióloga; Professora do Curso de Fonoaudiologia e do Programa de Pós-Graduação em Distúrbios da Comunicação Humana da Universidade Federal de Santa Maria, UFSM, Santa Maria, RS; Doutora em Letras pela Pontifícia Universidade Católica do Rio Grande do Sul.

Conflito de interesses: inexistente
Entre as formas de avaliar o perfil pragmático está a observação de habilidades comunicativas. Nessa avaliação, o ato comunicativo é o foco da análise quantitativa, sendo definido como momento em que a interação, adulto-criança, criança-adulto ou criança-objeto, é iniciada e se mantém concentrada. Ele termina quando o foco de atenção da criança muda ou há uma troca de turno. A partir da identificação do ato comunicativo, a autora ${ }^{1}$ propõe uma análise de 20 categorias baseadas em funções comunicativas. Elas abrangem tanto funções da aquisição típica ${ }^{1-3}$ quanto as funções que se sabem presentes na comunicação de sujeitos autistas ${ }^{4-12}$. Tais trabalhos têm buscado uma caracterização da linguagem que tem embasado algumas intervenções terapêuticas ${ }^{13-15}$.

De modo similar, a linha de cognição social, também inserida em uma visão pragmática, propõe uma análise do diálogo da díade a partir de um protocolo. Tal proposta tem sido utilizada em diversos trabalhos para análise de sujeitos 
do espectro autístico e também de deficientes visuais ${ }^{16-18}$.

A clínica de linguagem, baseada em uma visão de aquisição da linguagem em que o diálogo é a unidade de análise ${ }^{15}$, centra-se no funcionamento linguístico intersubjetivo. Ocupa-se do olhar sobre o diálogo adulto-criança na apropriação da língua enquanto objeto de ação, de conhecimento e de constituição subjetiva. No caso das verbalizações da criança autista, ocorre a presença de fragmentos da fala do outro, com características peculiares, que colocam questões específicas à interpretação da fala do autista pelo adulto ${ }^{19,20}$. As pesquisas demonstram diferenças entre a interpretação da mãe e a do terapeuta na análise dialógica das díades que podem ser exploradas na condução terapêutica, porque permitem pensar o funcionamento de linguagem em termos de posição enunciativa $^{21,22}$.

A partir da identificação de tais propostas, os objetivos deste artigo são analisar, comparativamente, os dados de linguagem obtidos através de dois protocolos, um de análise da interação mãecriança e outro de análise do desempenho pragmático da criança, e da análise dialógica da díade sujeito-mãe.

\section{APRESENTAÇÃO DOS CASOS}

Ao início dos atendimentos, as mães dos três sujeitos com características do espectro autista, que compõem esta amostra, foram esclarecidas sobre os propósitos do estudo, e Ihes foi deixado claro o direito de desistir de participar da mesma sem prejuízo ao tratamento do filho. Este estudo insere-se no projeto "Clínica da Subjetividade nos Retardos de Aquisição da Linguagem Oral: retardos de aquisição da linguagem oral secundários a grandes transtornos do desenvolvimento" aprovado pelo Comitê de Ética em Pesquisa institucional, sob número 0117.0.243.000-07. Em caso de aceite em participar do mesmo, os pais assinaram Termo de Consentimento Livre e Esclarecido, (TCLE) e iniciaram-se os procedimentos de coleta em um tempo aproximado de dezoito meses. O período inicial foi tomado como base para esta análise, escolhendo-se a primeira seção de filmagem.

As entrevistas iniciais foram realizadas nos dois primeiros encontros, nas quais se buscaram informações sobre os períodos pré e pós-natais até o momento da consulta fonoaudiológica. Nesse diálogo inicial com as mães, a incerteza sobre o desenvolvimento dos filhos era demonstrada pelo estado emocional conturbado de cada mãe, relatados com angústia, medo, incertezas e expecta- tivas frente ao novo tratamento em busca de auxílio ao filho.

A coleta dos dados foi realizada através da gravação em áudio e vídeo das sessões de terapia ocorridas na clínica-escola de atendimento fonoaudiológico, que ocorriam duas vezes por semana. Escolheu-se a primeira filmagem realizada para a análise deste artigo, com duração de 30 minutos, na qual cada sujeito foi filmado durante a interação dialógica com sua mãe, nas qual se puderam observar os comportamentos das crianças e de suas mães através da exposição dos mesmos a brinquedos compatíveis com a faixa etária de desenvolvimento do sujeito.

Ao término da coleta, a filmagem de cada sujeito foi transcrita e analisada seguindo o protocolo elaborado por Fernandes ${ }^{1}$, para avaliar o desempenho pragmático (atos e funções comunicativas infantis) e, o protocolo de Souza e Bosa ${ }^{23}$ com alterações sugeridas a partir de Souza, para a avaliação dos atos comunicativos verbais do comportamento materno e infantil.

As transcrições e atribuições das categorias protocolares foram conferidas pelos dois autores. Além da filmagem analisada, foram confrontadas a estas, as anotações feitas sobre as sessões de terapia, antes e após à filmagem, para a confirmação do tipo de interação visualizada na filmagem. Tais observações confirmaram os comportamentos maternos categorizados, pois os mesmos não diferiram entre o momento da sessão filmada e das outras sessões que ocorriam semanalmente.

A análise qualitativa buscou identificar o tipo de funcionamento linguístico a partir de aspectos como: funcionamento dos processos metafóricos e metonímicos permitido ou não pela presença de diálogo, ações linguísticas mais comuns (perguntas e respostas, jogos de nomeação, contagem, repetições...), presença de ecolalia e contextos em que ocorriam ou se intensificavam, entre outros.

Os resultados da análise serão apresentados dentro do caso, na seguinte ordem: histórico do caso, análise qualitativa do diálogo mãe-filho e análise quantitativa dos atos comunicativos e do diálogo mãe-filho. Nos quadros, sistematizam-se os dados obtidos com ambos os protocolos. Foram três os casos analisados:

- Caso 1- menino com idade de 3 anos e 5 meses.

- Caso 2- menino com idade de 2 anos e 1 mês.

- Caso 3- menino com idade de 4 anos e 6 meses.

Todos chegaram ao atendimento com diagnóstico prévio de espectro autístico estabelecido por outros profissionais, conforme será relatado nos resultados. 


\section{RESULTADOS}

\section{Caso 1}

O sujeito 1 (L), gênero masculino, tinha idade de 3 anos e 5 meses ao início dos atendimentos. Este compareceu ao Serviço de Atendimento Fonoaudiológico, encaminhado por neurologista, com queixa de atraso na fala e diagnóstico de espectro autista estabelecido por neurologista.

Não houve planejamento da gravidez, e seu conhecimento causou "susto" ao casal. Com o passar do tempo, a gravidez foi aceita com grande alegria. A mãe fez referência à necessidade de cuidados e repouso durante a gestação por ocorrência de sangramento durante os primeiros cinco meses. O nascimento foi a termo, através de cesariana. Após o sétimo dia do nascimento, o bebê precisou ser internado por icterícia.

Apresentou desenvolvimento neuropsicomotor típico, com balbucio no quinto mês e primeiras palavras no oitavo mês. Com aproximadamente um ano houve interrupção da fala, o que, segundo a mãe, aconteceu no mesmo período em que o pai esteve mais ausente em função do trabalho. Iniciou no maternal com um ano e oito meses. Naquele momento, voltou a falar algumas palavras soltas, parando novamente aos dois anos e seis meses. Compreendia somente ordens simples, sendo seletivo quanto às informações.

Sobre o brincar, a mãe afirmou a manipulação de forma repetitiva e fixação por objetos que giravam (ventilador, roda de carrinho, etc).

Apresentava humor instável, situações de agressividade com queixas de auto e heteroagressão referidas no ambiente escolar. Também, demonstrava dificuldade em permanecer na mesma atividade por muito tempo.

A seguir, são apresentados fragmentos da interação materna com L., nos quais se podem observar momentos de diretividade efetivados pela mãe durante ações realizadas pela criança. A mãe direcionava pedagogicamente o brincar do filho, determinando como o mesmo deveria manipular os objetos.

Tentativas da mãe em corrigir as emissões da fala de L. são constantes quando este comenta ou chama sua atenção. Nota-se que há uma preocupação materna maior em mostrar que o filho é capaz de reconhecer e nomear o que lhe é oferecido, conforme transcrição da sequência 1.

\author{
Sequência 1 \\ M: Preto, preto. \\ L: Peto. \\ M: Preto. \\ $L: A$. \\ M: O preto e o branco. \\ M: Tu não tá falando. \\ L: Uhm, im...tá bim, ih. \\ M: E os números que tem aí no telefone? Quais são \\ então? É o 1, o 2, o 3...qual outro tem? \\ L: Um. \\ M: O três..Qual outro tem? \\ L: Aii, micici.
}

$\mathrm{Na}$ sequência 1, composta de dois trechos da mesma transcrição, pode-se observar que a mãe oscila entre o ensinamento das cores e dos números, não ancorando um diálogo com L. O sujeito, por sua vez, responde às demandas da mãe em alguns momentos. Em outros apresenta fala de difícil interpretação. O fato mais importante a ressaltar é que em não havendo um diálogo não há funcionamento linguístico que permita o acesso à estrutura da língua. A cristalização em um processo de nomeação não explicita verbos, por exemplo, que são fundamentais tanto para a criação da noção de frase quanto para o acesso a estruturas morfológicas da língua. Com outro olhar, a Figura 1, sintetiza as análises da linguagem da criança e da mãe através dos protocolos.

$\mathrm{Na}$ análise do Figura 1, pode-se observar que o sujeito apresenta como principal evidência do espectro autístico a ausência de jogo compartiIhado no protocolo de Fernandes ${ }^{1}$. Já no protocolo de Souza e Bosa $^{23}$, ele compartilha pouco a atividade com o interlocutor (cabeça e olhar dirigidos ao interlocutor), apresenta muitas ecolalias e um brincar exploratório ainda muito presente. Por outro lado, possui muitos gestos declarativos, que sugerem que há boas perspectivas para a fala na abordagem cognitiva social que embasa este protocolo. No entanto, tal potencialidade não é investida pela mãe, já que a mesma não interpreta tais gestos, inserindo-os num contexto linguístico. Esse comportamento materno pode ser visualizado na presença de muitas perguntas e poucas respostas. Mesmo quando o menino fala, não entende seus enunciados. Apesar de realizar muitos comandos positivos, não intrusivos, os mesmos são caracterizados por uma diretividade pedagógica, como se viu na sequência 1. 


\begin{tabular}{|c|c|c|c|c|c|}
\hline \multicolumn{2}{|c|}{ Protocolo de Fernandes } & \multicolumn{4}{|c|}{ Protocolo de Souza e Bosa } \\
\hline $\begin{array}{l}\text { Categoria } \\
\text { funcional }\end{array}$ & Ocorrência & $\begin{array}{l}\text { Comportamentos } \\
\text { Maternos }\end{array}$ & Ocorrência & $\begin{array}{l}\text { Comportamentos infantis } \\
\text { e atos comunicativos }\end{array}$ & Ocorrência \\
\hline $\begin{array}{l}\text { Pedido de Objeto } \\
\text { (PO) }\end{array}$ & - & $\begin{array}{l}\text { Comportamentos } \\
\text { verbais(CV) }\end{array}$ & & $\begin{array}{l}\text { Cabeça e olhar dirigidos ao } \\
\text { interlocutor (COI) }\end{array}$ & 1 \\
\hline $\begin{array}{l}\text { Pedido de Ação } \\
\text { (PA) }\end{array}$ & 17 & Repetição (R) & 12 & $\begin{array}{l}\text { Cabeça e olhar para o } \\
\text { objeto manipulado pelo } \\
\text { interlocutor (COO) }\end{array}$ & 4 \\
\hline $\begin{array}{l}\text { Pedido de Rotina } \\
\text { Social (PS) }\end{array}$ & - & $\begin{array}{l}\text { Especularidade } \\
\text { diferida (ED) ou } \\
\text { expansão (E) }\end{array}$ & 2 & $\begin{array}{l}\text { Cabeça e olhar alternado } \\
\text { entre o objeto e interlocutor } \\
\text { ou toque no interlocutor } \\
\text { para solicitar o objeto } \\
\text { (gestos imperativos - Gl) }\end{array}$ & 3 \\
\hline $\begin{array}{l}\text { Pedido de } \\
\text { Consentimento } \\
\text { (PC) }\end{array}$ & - & Comentário (C) & 76 & $\begin{array}{l}\text { Gestos } \\
\text { declarativos (GD) }\end{array}$ & 11 \\
\hline $\begin{array}{l}\text { Pedido de } \\
\text { Informação (PI) }\end{array}$ & - & Perguntas (PE) & 46 & $\begin{array}{l}\text { Verbalizações ecolálicas } \\
\text { (VE) }\end{array}$ & 34 \\
\hline Protesto(PR) & 5 & Resposta(RES) & 8 & $\begin{array}{l}\text { Comentar ou perguntar } \\
\text { sobre objeto ou evento }\end{array}$ & 28 \\
\hline $\begin{array}{l}\text { Recolhimento do } \\
\text { Outro (RO) }\end{array}$ & 3 & Intrusiva verbal & & $\begin{array}{l}\text { Imitar ações arbitrárias } \\
(\operatorname{ImA})\end{array}$ & - \\
\hline Exibição(E) & - & $\begin{array}{l}\text { Comando } \\
\text { negativo(CN) }\end{array}$ & - & $\begin{array}{l}\text { Imitar ações instrumentais } \\
\text { (Iml) }\end{array}$ & - \\
\hline Comentário(C) & 21 & $\begin{array}{l}\text { Comando } \\
\text { incompleto }(\mathrm{Cl})\end{array}$ & - & Protesto (PR) & 5 \\
\hline $\begin{array}{l}\text { Auto- } \\
\text { regulatório(AR) }\end{array}$ & - & $\begin{array}{l}\text { Reprovação } \\
\text { negativa (RPN) }\end{array}$ & - & $\begin{array}{l}\text { Expressões de Protesto } \\
\text { (EP) }\end{array}$ & 4 \\
\hline Nomeação(N) & 21 & $\begin{array}{l}\text { Não intrusiva } \\
\text { verbal }\end{array}$ & & Auto-Regulatório(AR) & - \\
\hline Performativo (PE) & 76 & $\begin{array}{l}\text { Comando positivo } \\
\text { (CO) }\end{array}$ & 31 & Nomeação (N) & 21 \\
\hline Exclamativo (EX) & 29 & $\begin{array}{l}\text { Comando } \\
\text { incompleto }(\mathrm{Cl})\end{array}$ & - & Performativo(PE) & 76 \\
\hline Reativos (RE) & - & Regulação (Reg) & 4 & Exclamativo (EX) & 29 \\
\hline $\begin{array}{l}\text { Não-Focalizado } \\
\text { (NF) }\end{array}$ & - & & & Brincar estereotipado(Es & 11 \\
\hline Jogo $(J)$ & - & & & Exploratório (ex) & 12 \\
\hline Exploratório (EX) & 12 & & & Funcional (F) & 4 \\
\hline Narrativa (NA) & - & & & Simbólico (S) & 9 \\
\hline $\begin{array}{l}\text { Expressões de } \\
\text { Protesto (EP) }\end{array}$ & 4 & & & Balanceio & - \\
\hline $\begin{array}{l}\text { Jogo } \\
\text { Compartilhado (JC) }\end{array}$ & - & & & Flaping & - \\
\hline $\begin{array}{l}\text { Total de atos } \\
\text { comunicativos }\end{array}$ & 188 & & 179 & & 252 \\
\hline
\end{tabular}

Figura 1 - Apresentação sistematizada dos dados obtidos em ambos os protocolos para o sujeito $L$

\section{Caso 2}

O sujeito $2(A)$, também do gênero masculino, com idade inicial de 2 anos e 1 mês, foi encaminhado ao setor de linguagem por orientação da Fonoaudióloga do setor de motricidade oral do Serviço de Atendimento Fonoaudiológico da Universidade Federal de Santa Maria. A principal queixa referida pela família e escola foi a ausência de fala e comportamento social pouco presente.
O histórico gestacional foi acompanhado por situações de estado emocional conturbado e ocorrência de períodos de negação da gravidez que não foi planejada pelo casal. $O$ parto foi a termo e realizou-se cesárea de urgência. A necessitou de oxigênio e precisou permanecer em incubadora por 24 horas. Teve icterícia neonatal e realizou fototerapia por aproximadamente 4 dias. 
Sobre o desenvolvimento neuropsicomotor, iniciou marcha com apoio próximo dos 10 meses e marcha sem apoio com 1 ano e 3 meses. A mãe referiu não observar a emissão de nenhuma palavra com significado ou função comunicativa no desenvolvimento da linguagem do filho. Apresenta sono variado entre momentos de calma e inquietação. Dorme no quarto com os pais.

A sequência 2 é um exemplo do que se observou durante grande parte da sessão: as tentativas de interação da mãe com $A$. demonstrou a angústia desta em não obter respostas do filho as suas investidas. Utilizou diretividade e muitas vezes chegou a manipular o corpo do filho para ajustá-lo ao que desejava vê-lo fazer.

\section{Sequência 2}

M: Olha ali a bolha! Olha ali a bolha $A$.

A: Tatuiii.

M: Olha ali $A$. atrás de ti, olha lá tem outra. Outra ali A: Hummm, atuim

....

M: Vamô joga com a M. Vamô?

M: Olha ali! Chuta! (segura a perna do filho com a mão ensaiando o chute).

A: Ihh (tenta afastar-se sendo buscado pela mãe que o puxa pelo casaco).

Nos dois momentos transcritos da sequência 2 houve manifestações de interesse da criança na exploração do brinquedo, mas sua atenção era dispersada pelas tentativas da mãe em fazê-lo entender como os mesmos eram utilizados. Tais tentativas de dirigir e captar a atenção do filho pareceu ser respondida por A com reações de insatisfação manifestadas por forte selamento labial e emissão de jargões, acompanhados de balanceio. A mãe agiu como se estivesse vivendo um jogo de marionete, no qual o filho é tomado pelo seu desejo de ajustamento. Tal fato não é diretamente explicitado nos protocolos. Esses demonstram outras categorias que confirmam o diagnóstico de autismo, como se vê na Figura 2.

$\mathrm{Na}$ análise dos protocolos apresentada na Figura 2, evidencia-se que o espectro autístico destaca-se em várias categorias do protocolo de Fernandes ${ }^{1}$, caracterizadas pela falta de atenção compartilhada, brincar estereotipado, ausência de simbolismo e balanceios. Ainda, apresentou pedidos de ação e protestos, não identificados pela mãe na tentativa de fazê-lo "mostrar" algo funcional.

No protocolo de Souza e Bosa ${ }^{23}$, há restrito de compartilhamento das atividades com o interlocutor (cabeça e olhar dirigidos ao interlocutor), e quando aparecem são dirigidas pela ansiedade da mãe em dar continuidade às atitudes do filho. Em alguns momentos, quando o ato não se tornava extremamente dirigido, a criança ensaiava um brincar exploratório, mas logo abandonava pela intrusividade materna, numa demanda de mais perguntas do que respostas, e comandos positivos para captar a atenção do filho. Não há sugestão de boas perspectivas para a fala na abordagem cognitiva social que embasa o protocolo, pois $A$. não apresenta brincar simbólico e gestos declarativos e imperativos, havendo uma quase ausência de atenção compartilhada. $O$ interesse e investidas dessa mãe são evidentes, mas parecem perder-se pela forte ansiedade produzida que não a faz perceber, minimamente, os gestos e respostas do filho.

\section{Caso 3}

Com idade inicial de 4 anos e 6 meses, gênero masculino, o sujeito 3 (C) compareceu ao Serviço de Atendimento Fonoaudiológico encaminhado por Fonoaudióloga com queixa principal de dificuldade na fala, tendo diagnóstico de espectro autista realizado por médico neurologista.

Durante o período gestacional, houve a necessidade de repouso, pois a mãe apresentou ameaça de aborto a partir do sexto mês de gravidez, acompanhado de perturbado estado emocional. O nascimento foi por cesárea, a termo e sem particularidades.

Em relação ao desenvolvimento neuropsicomotor não houve referências de alterações ou atrasos. Na linguagem, após o sexto mês apresentou balbucio e, próximo de um ano, surgiram as primeiras palavras ("mama, papa, tata"), seguindose de "não qué xixi" para "não quero". Não usou gestos para se comunicar. Atualmente, não faz uso de pronomes e o uso de frases simples é restrito, sendo as mesmas produzidas soltas e fora de contexto. Apresenta fala ecolálica, acompanhada de jargões.

No brincar a mãe referiu perceber alguns rituais como rodar as rodinhas dos carrinhos, tampas, etc. Aprecia o brincar sozinho. Quando contrariado, apresentava crises de birra com tremores, atirandose no chão. Muitas vezes chorava sem motivo aparente. Tinha sono agitado, batendo-se muito na cama, onde dormia com os pais.

Sobre o comportamento observado na díade durante a interação, inicialmente, a mãe pareceu não se sentir à vontade em ter que brincar com o filho, demonstrando certa apreensão pela forma como $\mathrm{C}$ utilizava os brinquedos. Parecia estar analisando cada movimento do filho e categorizando o que percebia não ser adequado. Demonstrou maior interação no decorrer da atividade quando essas apresentavam foco mais pedagógico (ensino de letras e números), participando, ainda, de algumas 


\begin{tabular}{|c|c|c|c|c|c|}
\hline \multicolumn{2}{|c|}{ Protocolo de Fernandes } & \multicolumn{4}{|c|}{ Protocolo de Souza e Bosa } \\
\hline $\begin{array}{l}\text { Categoria } \\
\text { funcional }\end{array}$ & Ocorrência & $\begin{array}{l}\text { Comportamentos } \\
\text { Maternos }\end{array}$ & Ocorrência & $\begin{array}{l}\text { Comportamentos infantis } \\
\text { e atos comunicativos }\end{array}$ & Ocorrência \\
\hline $\begin{array}{l}\text { Pedido de Objeto } \\
\text { (PO) }\end{array}$ & - & $\begin{array}{l}\text { Comportamentos } \\
\text { verbais(CV) }\end{array}$ & - & $\begin{array}{l}\text { Cabeça e olhar dirigidos ao } \\
\text { interlocutor (COI) }\end{array}$ & 3 \\
\hline $\begin{array}{l}\text { Pedido de Ação } \\
\text { (PA) }\end{array}$ & 3 & Repetição (R) & - & $\begin{array}{l}\text { Cabeça e olhar para o } \\
\text { objeto manipulado pelo } \\
\text { interador (COO) }\end{array}$ & 3 \\
\hline $\begin{array}{l}\text { Pedido de Rotina } \\
\text { Social (PS) }\end{array}$ & - & $\begin{array}{l}\text { Especularidade } \\
\text { diferida (ED) ou } \\
\text { expansão (E) }\end{array}$ & - & $\begin{array}{l}\text { Cabeça e olhar alternado } \\
\text { entre o ogjeto e interador ou } \\
\text { toque no interador para } \\
\text { solicitar o objeto (gestos } \\
\text { imperativos - GI) }\end{array}$ & - \\
\hline $\begin{array}{l}\text { Pedido de } \\
\text { Consentimento } \\
\text { (PC) }\end{array}$ & - & Comentário $(\mathrm{C})$ & 30 & $\begin{array}{l}\text { Gestos } \\
\text { declarativos (GD) }\end{array}$ & - \\
\hline $\begin{array}{l}\text { Pedido de } \\
\text { Informação (PI) }\end{array}$ & - & Perguntas (PE) & 12 & $\begin{array}{l}\text { Verbalizações ecolálicas } \\
\text { (VE) }\end{array}$ & - \\
\hline Protesto(PR) & 16 & Resposta(RES) & 4 & $\begin{array}{l}\text { Comentar ou perguntar } \\
\text { sobre objeto ou evento }\end{array}$ & - \\
\hline $\begin{array}{l}\text { Recolhimento do } \\
\text { Outro (RO) }\end{array}$ & - & Intrusiva verbal & & $\begin{array}{l}\text { Imitar ações arbitrárias } \\
(\operatorname{ImA})\end{array}$ & - \\
\hline Exibição(E) & 14 & $\begin{array}{l}\text { Comando } \\
\text { negativo(CN) }\end{array}$ & - & $\begin{array}{l}\text { Imitar ações instrumentais } \\
\text { (Iml) }\end{array}$ & - \\
\hline Comentário(C) & - & $\begin{array}{l}\text { Comando } \\
\text { incompleto }(\mathrm{Cl})\end{array}$ & - & Protesto (PR) & 16 \\
\hline $\begin{array}{l}\text { Auto- } \\
\text { regulatório(AR) }\end{array}$ & - & $\begin{array}{l}\text { Reprovação } \\
\text { negativa (RPN) }\end{array}$ & - & $\begin{array}{l}\text { Expressões de Protesto } \\
\text { (EP) }\end{array}$ & 17 \\
\hline Nomeação(N) & - & $\begin{array}{l}\text { Não intrusiva } \\
\text { verbal }\end{array}$ & & Auto-Regulatório(AR) & - \\
\hline Performativo (PE) & 25 & $\begin{array}{l}\text { Comando positivo } \\
\text { (CO) }\end{array}$ & 28 & Nomeação (N) & - \\
\hline Exclamativo (EX) & 15 & $\begin{array}{l}\text { Comando } \\
\text { incompleto }(\mathrm{Cl})\end{array}$ & - & Performativo(PE) & 25 \\
\hline Reativos (RE) & - & Regulação (Reg) & - & Exclamativo (EX) & 15 \\
\hline $\begin{array}{l}\text { Não-Focalizado } \\
\text { (NF) }\end{array}$ & 13 & & & Brincar estereotipado(Es & 12 \\
\hline Jogo $(\mathrm{J})$ & - & & & Exploratório (ex) & 7 \\
\hline Exploratório (E) & 7 & & & Funcional (F) & 8 \\
\hline Narrativa (NA) & - & & & Simbólico (S) & 1 \\
\hline $\begin{array}{l}\text { Expressões de } \\
\text { Protesto (EP) }\end{array}$ & 14 & & & Balanceio & 2 \\
\hline $\begin{array}{l}\text { Jogo } \\
\text { Compartilhado (JC) }\end{array}$ & - & & & Flaping & - \\
\hline $\begin{array}{l}\text { Total de atos } \\
\text { comunicativos }\end{array}$ & 89 & & 74 & & 121 \\
\hline
\end{tabular}

Figura 2 - Apresentação sistematizada dos dados obtidos em ambos os protocolos para o sujeito A

iniciativas propostas pela criança como os apresentados no fragmento a seguir.

\section{Sequência 3}

M: Ó, zzzzzzzzz (demonstração do brincar com o avião).

C: jargão (parecia querer dizer algo à mãe pegando o brinquedo que estava com ela).

M: Tu não vai dar pra mim brincar contigo?
C: (pega dois aviões e segue "brincando" em círculos.)

M: Um só. Vem pra cá.

M: Ó, vem pra cá, ó.

M: Ó, vem pra cá! Zzzzz.

C: (segue na direção da mãe com seu avião).

...

M: Olha aqui! Quero vê se tu conhece essa letra, ó! C., ó! 
C: (observa o que a mãe está mostrando).

M: Então me diz que cor é essa aqui? Que cor é essa aqui?

$C: U$ " $C$ ".

M: O "C"! E a cor do "C" qual é? Qual é a cor do "C"? $C: O$ "C".

M: Que cor, é igual a qual? Que cor é essa? C: "C

Nos protocolos (Figura 3), percebe-se insatisfação e descontentamento de C, acompanhados de intensa produção de fala ecolálica. Isso ocorre em manifesto à diretividade da mãe, que aparecia nos momentos em que esta se posicionava de forma pedagógica, questionando o que o filho reconhecia numa tentativa de mostrar que ele sabia responder o que era perguntado. Percebe-se que a preocupação maior da mãe era com o futuro aprendizado do filho e que a mesma se refletia nos referidos comportamentos diretivos.

O brincar simbólico foi incentivado em alguns momentos, determinado por grande diretividade sempre que a mãe buscava o filho para the ensinar como poderia estar brincando com certo objeto, com comandos positivos, perguntas e comentários quantificados pelo protocolo de Souza e Bosa ${ }^{16}$. Momentos de simbolismo foram evidentes nessas tentativas de interação mãe-criança, trazendo maior imitação funcional e variada gama de comandos verbais, nomeação, pedidos e exclamações partidos do interesse da criança. Como há um número maior de comportamentos verbais, e estes aparecem em tipologia mais variada, tanto no protocolo de Fernandes ${ }^{1}$ quanto no de Souza e Bosa ${ }^{23}$, há menor número de gestos declarativos e imperativos neste sujeito, quando comparado ao sujeito L., que possui menor variedade de recursos verbais.

Em termos qualitativos, o diálogo entre L. e sua mãe, ocorre de modo que os processos metafóricos e metonímicos ficam dificultados, pois a mãe não dialoga, mas busca ensinar nomes e cores. Além disso, quando L. dá uma resposta, ela deixa à deriva a fala de L. (por exemplo, quando responde "o c"). Também demonstra que a mãe não é contingente na brincadeira, o que se reflete na sua fala, pois não oferece signos sintonizados com a brincadeira do filho.

\section{DISCUSSÃO}

Os aspectos observados nos três casos, de modo geral, evidenciaram situações semelhantes de diretividade e dificuldade materna no brincar com seus filhos durante as interações. A insegurança e o desejo de ver situações aparentemente simples sendo realizadas pelos filhos pareceu ser o foco das investidas dessas mães, que preferiam situações pedagógicas ao brincar livre.

Todas as crianças "pediam", cada uma em sua singularidade, a participação da mãe de forma livre, sem questionamento, sem o peso daquele olhar. Os sujeitos recusavam a diretividade exercida pelas mães, quase sempre pela intensificação de alguma característica comunicativa dessas crianças, como a emissão de jargões, ecolalias, mímica facial, balanceio ou birras. Mesmo assim, a tentativa em ver o filho realizando o que propunham, ou ensinavam, determinou a não-compreensão das mães acerca das tentativas de comunicação efetivadas pelos filhos.

Tais resultados confirmam estudos que demonstram que mães de crianças do espectro autista tendem a ser afetadas pelo perfil desajustado de suas crianças ${ }^{22}$ podendo ser extremamente "diretivas" em seu estilo de interação, exercendo um intenso controle sobre a atividade da criança ou, ao contrário, retirando-se da interação ${ }^{16}$. Esse controle acaba tendo efeito contrário ao desejo materno, que parece ser ensinar o filho. Em geral, tal posicionamento pode estar intensificando a produção de fala ecolálica ou jargonada e/ou, comportamento de ausência ou retirada da brincadeira por parte das crianças.

A partir de ambos os protocolos, foi possível visualizar comportamentos nas categorias performativas, exclamativas e nas verbalizações ecolálicas. Tais respostas foram efetivadas pelo sujeito ao que era buscado pelas mães durante os comentários, nas perguntas, comandos e repetições sobre as ações exercidas. Todas as categorias verificadas nos dois protocolos serviram de base reflexiva para a intervenção terapêutica, no entanto, o protocolo que abrange o diálogo mãe-filho foi o que mais se aproximou dos dados que podem ser obtidos em um olhar qualitativo ${ }^{23}$.

Retomando as sequências apresentadas de cada caso, os fragmentos demonstrados facilitam a identificação de ações para a análise qualitativa, como no sujeito $C$, que responde as investidas da mãe com negação à intensa diretividade na busca por respostas do filho. Nesses momentos, há uma negação que se manifesta e é respondida pela criança quando parece insatisfeita com a persistência da mãe. Esta demonstra não perceber e insiste diretivamente tentando conseguir do filho uma função autônoma.

Observa-se, em raros momentos das filmagens, o se entregar ao brincar, nas três mães, pois a diretividade observada impede o fluir na atividade lúdica. Esse resultado confirma a percepção de que pais de crianças autistas iniciam mais episódios de comunicação e usam mais frases imperativas do 


\begin{tabular}{|c|c|c|c|c|c|}
\hline \multicolumn{2}{|c|}{ Protocolo de Fernandes } & \multicolumn{4}{|c|}{ Protocolo de Souza e Bosa } \\
\hline $\begin{array}{l}\text { Categoria } \\
\text { funcional }\end{array}$ & Ocorrência & $\begin{array}{l}\text { Comportamentos } \\
\text { Maternos }\end{array}$ & Ocorrência & $\begin{array}{l}\text { Comportamentos infantis } \\
\text { e atos comunicativos }\end{array}$ & Ocorrência \\
\hline $\begin{array}{l}\text { Pedido de Objeto } \\
\text { (PO) }\end{array}$ & 8 & $\begin{array}{l}\text { Comportamentos } \\
\text { verbais(CV) }\end{array}$ & & $\begin{array}{l}\text { Cabeça e olhar dirigidos ao } \\
\text { interlocutor (COI) }\end{array}$ & 7 \\
\hline $\begin{array}{l}\text { Pedido de Ação } \\
\text { (PA) }\end{array}$ & 11 & Repetição (R) & - & $\begin{array}{l}\text { Cabeça e olhar para o } \\
\text { objeto manipulado pelo } \\
\text { interador (COO) }\end{array}$ & 7 \\
\hline $\begin{array}{l}\text { Pedido de Rotina } \\
\text { Social (PS) }\end{array}$ & - & $\begin{array}{l}\text { Especularidade } \\
\text { diferida (ED) ou } \\
\text { expansão (E) }\end{array}$ & - & $\begin{array}{l}\text { Cabeça e olhar alternado } \\
\text { entre o ogjeto e interador ou } \\
\text { toque no interador para } \\
\text { solicitar o objeto gesto } \\
\text { imperativo Gl }\end{array}$ & 9 \\
\hline $\begin{array}{l}\text { Pedido de } \\
\text { Consentimento } \\
\text { (PC) }\end{array}$ & - & Comentário (C) & 34 & $\begin{array}{l}\text { Gestos } \\
\text { declarativos (GD) }\end{array}$ & 1 \\
\hline $\begin{array}{l}\text { Pedido de } \\
\text { Informação (PI) }\end{array}$ & 8 & Perguntas (PE) & 35 & $\begin{array}{l}\text { Verbalizações ecolálicas } \\
\text { (VE) }\end{array}$ & 14 \\
\hline Protesto(PR) & 2 & Resposta(RES) & & $\begin{array}{l}\text { Comentar ou perguntar } \\
\text { sobre objeto ou evento }\end{array}$ & 32 \\
\hline $\begin{array}{l}\text { Recolhimento do } \\
\text { Outro (RO) }\end{array}$ & 1 & Intrusiva verbal & & $\begin{array}{l}\text { Imitar ações arbitrárias } \\
(\operatorname{ImA})\end{array}$ & 2 \\
\hline Exibição(E) & - & $\begin{array}{l}\text { Comando } \\
\text { negativo(CN) }\end{array}$ & - & $\begin{array}{l}\text { Imitar ações instrumentais } \\
\text { (Iml) }\end{array}$ & 1 \\
\hline Comentário(C) & 32 & $\begin{array}{l}\text { Comando } \\
\text { incompleto }(\mathrm{Cl})\end{array}$ & - & Protesto (PR) & 2 \\
\hline $\begin{array}{l}\text { Auto- } \\
\text { regulatório(AR) }\end{array}$ & - & $\begin{array}{l}\text { Reprovação } \\
\text { negativa (RPN) }\end{array}$ & - & $\begin{array}{l}\text { Expressões de Protesto } \\
(E P)\end{array}$ & 5 \\
\hline Nomeação(N) & 30 & $\begin{array}{l}\text { Não intrusiva } \\
\text { verbal }\end{array}$ & & Auto-Regulatório(AR) & - \\
\hline Performativo (PE) & 13 & $\begin{array}{l}\text { Comando positivo } \\
\text { (CO) }\end{array}$ & 29 & Nomeação (N) & 30 \\
\hline Exclamativo (EX) & 19 & $\begin{array}{l}\text { Comando } \\
\text { incompleto }(\mathrm{Cl})\end{array}$ & - & Performativo(PE) & 13 \\
\hline Reativos (RE) & - & Regulação (Reg) & - & Exclamativo (EX) & 19 \\
\hline $\begin{array}{l}\text { Não-Focalizado } \\
\text { (NF) }\end{array}$ & - & & & Brincar estereotipado(Es & 4 \\
\hline Jogo $(J)$ & - & & & Exploratório (ex) & 3 \\
\hline Exploratório (E) & 15 & & & Funcional $(\mathrm{F})$ & 4 \\
\hline Narrativa (NA) & - & & & Simbólico (S) & 9 \\
\hline $\begin{array}{l}\text { Expressões de } \\
\text { Protesto (EP) }\end{array}$ & 5 & & & Balanceio & 1 \\
\hline $\begin{array}{l}\text { Jogo } \\
\text { Compartilhado (JC) }\end{array}$ & - & & & Flaping & - \\
\hline $\begin{array}{l}\text { Total de atos } \\
\text { comunicativos }\end{array}$ & 144 & & & & 160 \\
\hline
\end{tabular}

Figura 3 - Apresentação sistematizada dos dados obtidos em ambos os protocolos para o sujeito C

que pais de crianças em desenvolvimento típico, como o proposto em alguns estudos ${ }^{12}$. Por outro lado, observa-se que, quando as mães deixam de dirigir a atividade e partem para um brincar livre, os sujeitos participaram mais naturalmente da atividade materna. Nesses momentos, a linguagem da mãe sintonizava-se com as ações dos filhos, dando lugar ao funcionamento dos processos metafóricos e metonímicos ${ }^{19-20}$.
Nos fragmentos apresentados para análise qualitativa dialógica da díade, o que pareceu uma falha da criança em compartilhar o foco de atenção com a mãe, na verdade pôde receber outro sentido: ser uma negação da criança em fazer o que the é imposto ${ }^{15,22}$. Essa relação mostrou-se comum nos três sujeitos, nos quais protestos, comentários, exclamações e atos performativos assumem função e demonstram integração do que a criança 
quer comunicar ao que o outro comenta, questiona e impõe. Portanto, a análise qualitativa apresentouse, nesse sentido, complementar à análise por meio dos protocolos ${ }^{18}$, uma vez que estes trabalham mais com o produto dos comportamentos infantis e maternos. Eles permitem a comparação entre sujeitos e intrasujeito, mas há detalhes do funcionamento comunicativo entre mãe e filho que não são captados por protocolos, mas pelo confronto entre a história da díade e a observação do brincar e do diálogo mãe-filho.

\section{CONCLUSÃO}

Os resultados sugerem que o protocolo que analisa categorias maternas e categorias infantis provê resultados mais próximos aos dados encontrados na análise qualitativa da dialogia mãe-filho.

A análise qualitativa, por outro lado, embora não possua uma padronização junto a crianças em desenvolvimento típico, permite captar a singularidade de cada criança e as formas de comunicação que emergem a partir do comportamento materno, ou seja, o funcionamento de linguagem intersubjetivo. A partir de tais dados é possível traçar metas terapêuticas com a díade e não apenas para a criança.

Portanto, pode-se observar que os protocolos demonstram dados quantitativos da criança e da mãe, o que pode permitir a comparação entre os sujeitos e destes com sujeitos portadores de outros distúrbios do desenvolvimento e da linguagem, bem como a sujeitos em aquisição típica de linguagem. Já o olhar qualitativo do diálogo, em confronto com a história do sujeito, permite observar a relação entre o discurso materno e seu funcionamento dialógico com o filho. Permite observar se a mãe está ou não conseguindo ancorar a linguagem para o funcionamento ou não dos processos metafóricos e metonímicos e possíveis razões subjetivas e objetivas para fazê-lo ou não.

\begin{abstract}
Background: language in autism. Procedures: the data obtained through two protocols and also from the dialogical analysis of the pair mother-son were analyzed comparatively and the therapeutic implications of these analysis were discussed. The sample was made of three children between 2 years and 1 month and 4 years and 6 months with diagnosis within the autistic spectrum. The collect was carried out through video recording of mother-child play interaction sessions during 30 minutes. Data analysis procedures were: video transcription and checking, application of two protocols, one concerning mother-son interaction analysis and another one child communicative behaviors, and a qualitative analysis of the linguistic function with the pair. Results: the mother-child interaction protocol showed similar category frequencies between the three mothers, and elevated frequency of questions and intrusive directivity. In the same protocol, children demonstrated exploratory and functional play, verbal and non-verbal stereotypes, which were also observed in the child communicative behaviors protocol. The mother-child interaction protocol allows to better show the mother-child behavior linkage than the communicative one, but only qualitative analysis exposed the nature of this linkage. Conclusion: the interactional protocol showed better information for therapeutic plan than the child communicative behaviors did. That protocol, with qualitative analysis, permitted more qualified election of therapeutic strategies.
\end{abstract}

KEYWORDS: Child Language; Autistic Disorder; Language Disorders

\section{REFERÊNCIAS}

1. Fernandes FDM. Pragmática. In: Andrade CFR, Befi-Lopes DM, Fernandes FD, Wertzner $H F$. ABFW: teste de linguagem infantil nas áreas de fonologia, vocabulário, fluência e pragmática. Barueri: Pró-Fono; 2004,89p.

2. Cervone LM, Fernandes FDM. Análise do perfil comunicativo de crianças de 4 e 5 anos na interação com adulto. Rev Soc Bras Fonoaudiol. 2005; 10(2):97-105.

3. Hage SRV, Resegue MM, Viveiros DCS, Pacheco EF. Análise do perfil das habilidades pragmáticas em crianças pequenas normais. Pró-Fono. 2007; 19(1):49-58.

4. Molini-Avejonas DR, Fernandes FDM. Alterações pragmáticas, cognitivas e sociais em crianças com autismo: revisão de literatura. Rev Soc Bras Fonoaudiol. 2004; 9(3):179-86. 
5. Bosa C, Callias M. Autismo: breve revisão de diferentes abordagens. Psicol Reflex Crit. 2000; 13(1):167-77.

6. Cardoso C, Fernandes FDM. Relação entre os aspectos sócio cognitivos e perfil funcional da comunicação em um grupo de adolescentes do espectro autístico. Pró-Fono. 2006; 18(1):89-98.

7. Miilher LP, Fernandes FDM. Análise das funções comunicativas expressas por terapeutas e pacientes do espectro autístico. Pró-Fono. 2006; 18(3): 239-48.

8. Sousa-Morato PF, Fernandes FDM. Análise do perfil sócio-comunicativo quanto à adaptação sóciocomunicativa em crianças do espectro autístico. Rev Soc Bras Fonoaudiol. 2006; 11(2):70-4.

9. Sousa-Morato PF, Fernandes FDM. Correlatos entre o perfil comunicativo e adaptação sóciocomunicativa no espectro autístico. Rev. CEFAC. 2009; 11, (supl.2): 227-39.

10. Fernandes FDM, Teles P. Linguagem nos transtornos do espectro autístico. Rev Soc Bras Fonoaudiol. 2005; 10(4):207-10.

11. Diehl SF. Autism spectrum disorder: the context of speech-language pathologist intervention. Lang Speech Hear Serv Schools. 2003; 34(3):177-9.

12. Loveland K.A., et. al. Speech acts and the pragmatics deficits in autistic children. J Speech Hear Res. 1988; 47:593-604.

13. Fernandes FDM. Resultados de terapia fonoaudiológica com adolescentes com diagnóstico incluído no espectro autístico. Pró-Fono. 2005; 17(1):67-76.

14. Fernandes FDM. Fonoaudiologia e autismo: resultado de três diferentes modelos de terapia de linguagem. Pró-Fono. 2008; 20(4): 267-72.
15. Balestro JI, Souza APR, Rechia IC. Terapia fonoaudiológica em três casos do espectro autístico. Rev Soc Bras Fonoaudiol. 2009; 14(1):129-35.

16. Souza $A D$, Bosa $C A$, Hugo $C N$. As relações entre deficiência visual congênita, condutas do espectro do autismo e estilo materno de interação. Estud Psicol. 2005; 22(4):355-64.

17. Coelho ACC, lemma EP, Lopes-Herrera SA. Relato de caso: privação sensorial de estímulos e comportamentos autísticos. Rev Soc Bras Fonoaudiol. 2008; 13(1): 75-81.

18. Oliveira JP, Marques SL. Análise da comunicação verbal e não-verbal de crianças com deficiencia visual durante interação com a mãe. Rev Bras Educ Espec. 2005; 11(3): 409-28.

19. De Lemos CTG. Corpo e corpus. In: Leite NVA, organizador. Corpolinguagem: gestos e afetos. Campinas: Mercado das Letras; 2003. p. 21-9.

20. De Lemos CTG. Das vicissitudes da fala da criança e de sua investigação. Cad Estud Linguíst. 2002; (42):41-69.

21. Vorcaro A. A clínica psicanalítica e fonoaudiológica com crianças que não falam. Dist Comun. 2003; 15(2):265-87.

22. Laznik MC. A voz da sereia: o autismo e os impasses na constituição do sujeito. Salvador: Ágalma; 2004.

23. Souza AD, Bosa C. Protocolo de Registro de Transcrição dos Episódios de Atividades Conjuntas. (Instrumento de pesquisa não-publicado). Porto Alegre (RS): Universidade Federal do Rio Grande do Sul; 2002c.

24. Winnicott DW. (1975). O brincar e a realidade. Rio de Janeiro: Imago. (Original publicado em 1971).
http://dx.doi.org/10.1590/S1516-18462010005000073

RECEBIDO EM: 20/08/2009

ACEITO EM: 15/03/2010

Endereço para correspondência:

Ana Paula Ramos de Souza

Rua Raposo Tavares, 134 ap. 401

Santa Maria - RS

CEP: 97015-560

E-mail: ramos1964@uol.com.br 